American Journal of Applied Sciences 9 (1): 107-110, 2012

ISSN 1546-9239

(C) 2012 Science Publications

\title{
Dynamic Capability and Its Effects on Firm Performance
}

\author{
${ }^{1}$ Kuo-Wei Lin and ${ }^{2}$ Kai-Ping Huang \\ ${ }^{1}$ Department of International Business, College of Management, \\ Hsuan Chuang University, R.O.C., Taiwan \\ ${ }^{2}$ School of Management, Faculty of Business, \\ University of Technology, Sydney, Australia
}

\begin{abstract}
Problem statement: The study has been mainly attempted as an extension to previous studies made on dynamic capabilities and their necessity in organizational firms for goals' accomplishments. Approach: The literature review illustrates the effects of dynamic capabilities on product innovation, firm performance and environmental dynamism. The researches of different authors and theorists on the subject of dynamic capability have been consulted and analysed to present a research study through this study. Results: The study has provided with a detailed understanding of the dynamic capability strategies that have been found to be highly significant in successful organizational performance. The development of different propositions also reflect the increasing importance of dynamic capabilities in organizations that managers are integrating in their strategic management practices all the more from before. Conclusion: This study reveals that the availability of dynamic capabilities imply that a firm may be protected from the negative impacts through planned strategic measures intended to encounter challenges and uncertainties and yet perform to the utmost level and succeed in achieving organizational goals and objectives.
\end{abstract}

Key words: Dynamic capabilities, product innovation, firm performance, environmental dynamism, external surroundings, organizational performance, dynamic capability strategies, gaining competitive advantage, alternative systems

\section{INTRODUCTION}

Studies have reflected that innovativeness has the ability to alter the strategies of small and medium enterprises in their invention, development, introduction and commercialization of innovative products. Dynamic capabilities make organizations capable of such innovativeness by planning out suitable measures and finding out their impacts on the accomplishment of organizational goals (Branzei and Vertinsky, 2006; Thiel, 2010). In the global world of competition, sustainable competitive advantage has been found to be of great importance and need in both marketing and strategic management of a business. Alternative systems are being focussed in the current researches conducted on marketing and management of organizations that tend to prove the worth of dynamic capabilities within organizations (Ali et al., 2010). Propositions in regard to the use of dynamic capabilities in organizations with respect to product innovation, environmental dynamism and firm performance are being continuously developed for achievement of organizational goals.

\section{MATERIALS AND METHODS}

The study is to provide several constructs in relation to dynamic capabilities and their necessity in firms for goals' acheievment based on the following literature review:

Dynamic capabilities and product innovation: With more and more focus on the development of innovative products, researchers believe that product innovation can be considered to be a method of renewing organizational activities towards achievement of goals. Such renewals include developments in organizational competencies, encouraging changes in the marketing of products enhancing improvements over the rival companies (Danneels, 2002; Minetaki and Takemura, 2010). In the modern world of competitions and changing technological surroundings, innovation in products is considered as "major drivers" that enables a firm to reach to its customers by providing them with greater value than their competitors thus "gaining competitive advantage" (Hacklin et al., 2009). Technological changes have a major association with

Corresponding Author: Kuo-Wei Lin, Department of International Business, College of Management, Hsuan Chuang University, R.O.C., Taiwan 
product innovation. It is a challenging issue for different organizations to adapt to the changes in the business environment. Firms may require to make changes in its "knowledge and capabilities" that focus on the management practices concerning organizational reactions to changes thus leading to product innovation (Benner, 2009).

Product innovation, although seem to have become a very important aspect of managerial decision-making, yet it has been obtained by researchers that innovative techniques may be affected by several factors that "promote the firm's capacity to innovate" (Spanos and Prastacos, 2004). Integration and development of dynamic capabilities have been found to have long-term positive impacts on the competitive advantage of a firm. Marketing capabilities involving the understanding of customers as well as technological capabilities that allow firms to integrate different expertise into the production and manufacturing processes are equally significant in enabling companies to "solve technical problems, to implement new technical processes and tools and to develop prototypes" (Marsh and Stock, 2003; Yien et al., 2011). Dynamic capabilities that focus on configuration of resources in beneficial manner matching up with the changing business requirements involve mechanisms that are significant in product innovation (O'Connor, 2008).

Dynamic capabilities can be found to be positively related to innovation in products since product innovation is a very significant aspect in the global competitive market where constantly the economy as well as the technology is changing at a random pace. To cope up with the changing scenario, dynamic capabilities within organizations enable the organizational management to take up measures that facilitate in innovativeness that is demanded in the market. This also focuses on the advanced use of technology as well as the changing economical environment. Product innovation has also become necessary owing to the changing demands of the customers. Dynamic capabilities enhance the understanding of such changes that eventually help a firm in undertaking innovative measures. The development of this proposition can be thus said to have a significant impact on the performance of an organization. Thus:

Proposition one: Dynamic capabilities are positively related to product innovation.

Dynamic capabilities and firm performance: The needs for dynamic capabilities arise in the context of economic changes in the global marketing world. Researchers have obtained that improved changes in the abilities of an organization may reflect positive effects on the performances of the firm (Judge et al., 2009). Dynamic capabilities of a firm also include the firm's taking measures to go into alliances. Researchers have found several reasons behind these alliances that include collection of resources that may balance each other, the costs and risks may be mutually distributed that may occur while carrying out expensive and indecisive projects. Also, required resources, capabilities and knowledge may be gained through these measures (Jiang et al., 2010). Marketing capabilities have a great influence on the economic performance of an organization in the global market. Higher returns can be expected when the available resources of a company are integrated into dynamic capabilities. The integration process is specific to a firm, providing value to its customers as well as formulated in a manner that can neither be substituted nor imitated (Blesa and Ripolles, 2008).

The performance of a firm is also highly related to dynamic capabilities. As it has been obtained through earlier studies, firms may enter into alliances that have a positive influence in the achievement of the organizational goals. Also, marketing capabilities have a greater participation in the improvement of a firm's performance as they are directly related to the accomplishments of the company in relation to the consumer demands and expectations and fulfilling them to the utmost level, thus increasing the revenues as well as preferences for the company. Performance of a firm is to a large extent dependent on the dynamic capabilities of the firm since the successful performance of a firm involves several issues in regard to correct decision making, suitable selection and allocation of resources, factors that are effectively handled by dynamic capabilities. Thus this proposition is also developing in the modern business world and can be seen to have immense positive effects. That is:

Proposition two: Dynamic capabilities are positively related to firm's performance

Dynamic capabilities and environmental dynamism: Researchers have found that the ability of managers and leaders to effectively manage the strategic policies of their organizations in ever-changing environments seems to be a debatable issue. In the face of dynamic environments prevailing within organizations affected by factors including product and technology innovation, international competition as well as pioneering activities, organizational leaders have to continuously face challenges in effectively accomplishing organizational objectives. These challenges are integrated into dynamic capabilities with the belief that 
Am. J. Applied Sci., 9 (1): 107-110, 2012

firms are capable of creating and integrating resources in innovative manner (Eisenhardt et al., 2010). Researchers have stressed on the issue that development of new resources needs to be an ongoing process for an organization and dynamic capabilities are significant in dealing with "new market demands" that enables a firm to sustain, grow and develop in the changing environmental global business world (Zhang, 2007). Organizations performing in different industries and varied market environments have been found to be facilitated by the dynamic ability of the organizational leaders and managers to make strategic decisions towards achieving innovative products and technology and attaining competitive advantage (Zhang, 2007).

In the changing business world, it can be realized that the business environment is constantly facing challenges in the face of changes occurring in the internal as well as external surroundings. Challenges may occur for a firm in terms of its competing with its rival companies for features that may be similar among them and attractive to customers equally. Dynamic capabilities enable an organization to face such challenges through taking different measures towards effective and efficient management of goals and objectives. The various affecting factors may thus be dealt with successfully that would protect an organization from having any negative impact. Business environment can be understood to be a very important factor that may impact a firm either positively or negatively depending on the circumstances. A firm's remaining prepared with all possible measures is thus preferable for any organization. Hence, this proposition is equally relevant in the contribution of dynamic capability. That is:

Proposition three: The degree of environmental dynamism is positively related to the contribution of dynamic capability.

\section{RESULTS}

Dynamic capabilities facilitate a company in its improved performances, its innovativeness in terms of products and advanced use of technology as well as prepare a firm to survive in the ever-changing business environment. Based on the advantages of dynamic capabilities in organizational management, different propositions are developing towards the greater understanding of the needs to integrate dynamic capabilities in organizations for the betterment of performances.

Dynamic capabilities have also been found to be an important part in the product innovations and advanced uses of technology in different organizations. It can be realized that dynamic capability focuses on the changing needs of both the organizations as well as its customers and prepares a firm accordingly to face the challenges encountered due to the changing business environment. In other words, the concepts of dynamic capabilities help organizations to adapt to the changes in the business environment. When dynamic capabilities are involved in product innovation and technological changes, the companies also get assisted through the solutions available to technical problems and implementation of new techniques and processes. The greater need and importance of dynamic capabilities arise owing to the constant changes that are prevailing in the business environment. Marketing capabilities have been found to have a great positive influence on the economic performance of an organization in the global market.

\section{DISCUSSION}

From the studies conducted and the significance of the dynamic capabilities as observed in relation to organizational performances and accomplishments of goals and objectives, it may be drawn as a conclusion that dynamic capabilities have a major role to play in the organizational management where the leaders and managers are facilitated in their decision making towards organizational success. Dynamic capabilities can be observed as focusing on various aspects of a firm dealing with product innovations and technological advances, handling and facing challenges from the changing business environment as well as improving the performance of the firm as a whole. The development of different propositions also reflect the increasing importance of dynamic capabilities in organizations that managers are integrating in their strategic management practices all the more from before. While it can be realized that negative effects may occur on the performances and success of a company, this study reveals that the availability of dynamic capabilities imply that a firm may be protected from the negative impacts through planned strategic measures intended to encounter challenges and uncertainties and yet perform to the utmost level and succeed in achieving organizational goals and objectives.

\section{REFERENCES}

Ali, S. L.D. Peters, H.W. He and F. Lettice, 2010. Market based organisational learning, dynamic, and substantive capabilities: An integrative framework. J. Strategic Market., 18: 363-377. DOI: 10.1080/0965254X.2010.497846 
Benner, M.J., 2009. Dynamic or static capabilities? Process management practices and response to technological change. J. Product Innov. Manage., 26: $\quad 473-486$. DOI: $10.1111 / \mathrm{j} .1540-$ 5885.2009.00675.x

Blesa, A. and M. Ripolles, 2008. The influence of marketing capabilities on economic international performance. Int. Market. Rev., 25: 651-673. DOI: 10.1108/02651330810915574

Branzei, O. and I. Vertinsky, 2006. Strategic pathways to product innovation capabilities in SMEs. J. Business Ventur., 21: 75-105. DOI: 10.1016/j.jbusvent.2004.10.002

Danneels, E., 2002. The dynamics of product innovation and firm competences. Strategic Manage. J., 23: 1095- 1121. DOI: 10.1002/smj.275

Eisenhardt, K.M., N.R. Furr and C.B. Bingham, 2010. Microfoundations of Performance: Balancing efficiency and flexibility in dynamic environments. Organ. Sci., 21: 1263-1273. DOI: 10.1287/orsc. 1100.0564

Hacklin, F., M. Inganas, C. Marxt and A. Pluss, 2009. Core rigidities in the innovation process: A structured benchmark on knowledge management challenges. Int. J. Technnol. Manage., 45: 244266. DOI: 10.1504/IJTM.2009.022651

Jiang, R.J., Q.T. Tao and M.D. Santoro, 2010. Alliance portfolio diversity and firm performance. Strategic Manage. J., 31: 1136-1144. DOI: 10.1002/smj.869

Judge, W.Q., I. Naoumova and T. Douglas, 2009. Organizational capacity for change and firm performance in a transition economy. Int. J. Hum. Res. Manage., 20: 1737-1752. DOI: $10.1080 / 09585190903087107$
Marsh, S.J. and G.N. Stock, 2003. Building dynamic capabilities in new product development through intertemporal integration. J. Product Innov. Manage., 20: 136-148. DOI: $10.1111 / 1540-$ 5885.2002006

Minetaki, K. and T. Takemura, 2010. The productivity and human capital in the japanese software industry: The view of service innovation. Am. J. Econ. Bus. Admin., 2: 73-77. DOI: 10.3844/ajebasp.2010.73.77

O’Connor, G.C., 2008. Major innovation as a dynamic capability: A systems approach. J. Product Innov. Manage., 25: 313-330. DOI: 10.1111/j.15405885.2008.00304.x

Spanos, Y.E. and G.P. Prastacos, 2004. The effects of environment, structure, and dynamic capabilities on product innovation strategy. Int. J. Entrepreneurship Innov. Manag., 4: 620-638. DOI: 10.1504/IJEIM.2004.005852

Thiel, M., 2010. Innovations in corporate social responsibility from global business leaders at panasonic, thomson reuters and nanyang business school. Am. J. Econ. Bus. Admin., 2: 194-200. DOI: 10.3844/ajebasp.2010.194.200

Yien, J.M., K.H. Chen, K.P. Huang and C.J. Huang, 2011. Managerial decision and resource reallocation: A dynamic capability perspective. J. Soc. Sci., 7: 632-634. DOI: 10.3844/ajssp.2011.632.634

Zhang, M.J., 2007. IS support for top managers' dynamic capabilities, environmental dynamism, and firm performance: An empirical investigation. J. Bus. Manage., 13: 57-77. 